\title{
The prevalence of tic disorders in children and adolescents in Brazil
}

\author{
A prevalência dos transtornos dos tiques em crianças e adolescentes no Brasil \\ Helvio L. Alves, Elizabeth M. A. B. Quagliato
}

\begin{abstract}
Tourette syndrome (TS) and tic disorders represent events of familiar magnitude characterized by involuntary movements and/or vocalization. To determine the prevalence of TS/tic disorders we studied a sample of 762 subjects (388 M, 374 F), between 1992 and 1997 , age 6 to 43 years old, taken out of a population of 10,155 subjects (4,918 M, 5,237 F; age: 3-56 years old). A structured 4-item questionnaire, direct interview (multistaged), $>1 \mathrm{yr}$ follow-up, were used. 9,565 subjects $(4,614 \mathrm{M}, 4,951 \mathrm{~F})$ sent back the questionnaires, 3,354 of these (1,671 M, 1,683 F) with positive answers to tics. 42 subjects (31 M, $11 \mathrm{~F}$, age: 7-21 years old, mean: 11 years old) met the DSM-III-R criteria. The total minimal prevalence of TS is $0.43 \%$, with a 3:1 ratio male/female. The minimal prevalence of chronic tic disorder is $2.27 \%$. The total minimal prevalence for tic disorders at all is $2.91 \%$. No special education students participation.
\end{abstract}

Keywords: Tourette syndrome, tic disorders, epidemiologic community prevalence study.

\section{RESUMO}

Síndrome de Tourette e transtornos de tiques representam eventos de magnitude familiar caracterizados por movimentos involuntários e/ou vocalização. Para determinar a prevalência de TS/transtornos de tiques, estudamos uma amostra de 762 indivíduos (286 M, 376 F), entre 1992 e 1997, de 6 a 43 anos de idade, retirados de uma população de 10.155 indivíduos (4.918 M, 5.237 F, idade: 3-56 anos). Questionário de avaliação inicial (4 itens), entrevista direta, follow-up >1 ano, foram utilizados. 9.565 indivíduos (4.614 M, 4.951 F) retornaram seus questionários, $3.354(1.671 \mathrm{M}, 1.683 \mathrm{~F}$ ), com respostas positivas para tiques. 42 sujeitos (idade $31 \mathrm{M}, 11 \mathrm{~F}, 7-21$ anos, média: 11 anos) preencheram os critérios diagnósticos do DSM-III-R. A prevalência total mínima para TS é de 0,43\% (3 M:1 F), e para transtornos de tiques crônicos é de 2,27\%. A prevalência total mínima para transtornos dos tiques é 2,91\%. Nenhuma participação de estudantes de classe especial.

Palavras-chave: síndrome de Tourette, transtornos dos tiques, estudo epidemiológico de prevalência na comunidade.

Tics are brief and repetitive contractions of muscular groups, stereotyped, more commonly involving facial muscles, neck and arms. It causes sudden movements of the corporal parts involved and it may be localized in the trunk, legs and in muscles that intervene in respiration and phonation, leading to emission of sounds (vocalizations). Both motor and vocal tics can be simple or complex, and they may be part of a spectrum ranging from transient tic disorder (TTD), simple (SCTD) or multiple chronic tic disorder (CMTD) to Tourette syndrome (TS). Once considered a rare disorder, the most recent studies have reported prevalence ranging from 0.10 to $3.8 \%$ but prevalence as low as $0.043 \%$ and as high as $5.26 \%$ has been reported ${ }^{1,2,3,4,5}$.

As in our country there has not been a previous study on tic disorders, we decided to start this investigation with the scope to determine TS/tic disorders prevalence in a cohort of students and to follow-up those identified subjects. We followed the DSM-III-R criteria $3^{\text {rd }}$ ed., and The Tourette Syndrome Classification Study Group (TSCSG) $)^{6,7}$.

\section{METHOD}

An amount of 15,000 questionnaires were sent to school directors to be distributed to the students. The aim was to reach at least half of the students in the city. 10,155 students (4,918 male, 5,237 female) filled out the questionnaires and sent them back. All of these students, who were a representative number of the Indaiatuba's students' population, were attending the school system in the year of 1992 in the city of Indaiatuba, State of Sao Paulo, Brazil. They were taken from kindergarten to high-school and technical courses. Their

Departamento de Neurologia, Universidade Estadual de Campinas, Campinas SP, Brazil.

Correspondence: Helvio Leite Alves; Rua Christiano Steffen, 152; 13330-270 Indaiatuba SP, Brasil; E-mail: hlalves@outlook.com

Conflict of interest: There is no conflict of interest to declare.

Received 15 April 2014; Received in final form 29 August 2014; Accepted 17 September 2014. 
mean age was 11.2 years old (SD: 4.3; median 1; range: 2-56 years old). $85.17 \%$ were aged between 2 to $15 ; 7.12 \%$ were aged between 16 to 21 and $2.5 \%$ from 22 to 56 years old. 512 students $(5.0 \%)$ did not refer their age. According to the Brazilian Institute of Geography and Statistics (IBGE), this city had a population of 100,947 inhabitants in the 1991 census (50,969 male, 49,978 female), with a population of 25,309 students, out of which 21,704 were above 5 years old [Child Education: up to 6 years old; Fundamental Teaching I ( $1^{\text {st }}$ to $4^{\text {th }}$ grade, commonly students from 7 to 10 years old); Fundamental Teaching II ( $5^{\text {th }}$ to $8^{\text {th }}$ grade, commonly students from 11 to 15 years old); and Middle Teaching (commonly students from 16 to 18 years old) a total of 21,626 students]. Our population of students over 22 years old were those who took part in the "Brazilian late teaching how to read and write program" and comprised $2.56 \%$ of the total. Age 6 to 18 encompassed 91.7\% (Figure 1). Special education students were not included. Students from the rural area were represented by one school, which was representative of this area. Schools of the south, north, west and east regions were included. Students from 18 schools among the 22 intended ones were evaluated. Most of the schools were public. One private school participated and another private one accepted the inclusion in the study but did not send the questionnaires back. These two schools were similar regarding the social characteristics of the students.

\section{That research was divided into three phases An instructional phase}

A series of lectures about the Tourette syndrome with video exposition took place in the months of September and October (1992). They were directed to people from the Department of Education of the Indaiatuba city Administration, school directors and teachers. During one month all the schools, in all periods, had their teachers taught how to identify tics. The rationale for teachers' training was to help parents fill out the questionnaires with direct assistence to them, which could help decrease the number of false negative responses.

\section{A screening phase}

In November 1992 the questionnaires were given to the school directors to be distributed among all students in their schools. The questionnaire should be filled out by parents. In the schools of lower cultural level students, the questionnaires should be filled out with their teachers' assistance, in the students' final evaluation meeting. Four schools had some troubles with the questionnaire distribution and were not included in the study. The 4-item questionnaire inquired about the most common motor and vocal tics, simple and complex, and it also included a sub-item of obsessive compulsive symptoms and a possibility to describe any other not included tic. The questionnaire items were elaborated having the tic literature been taken into account.

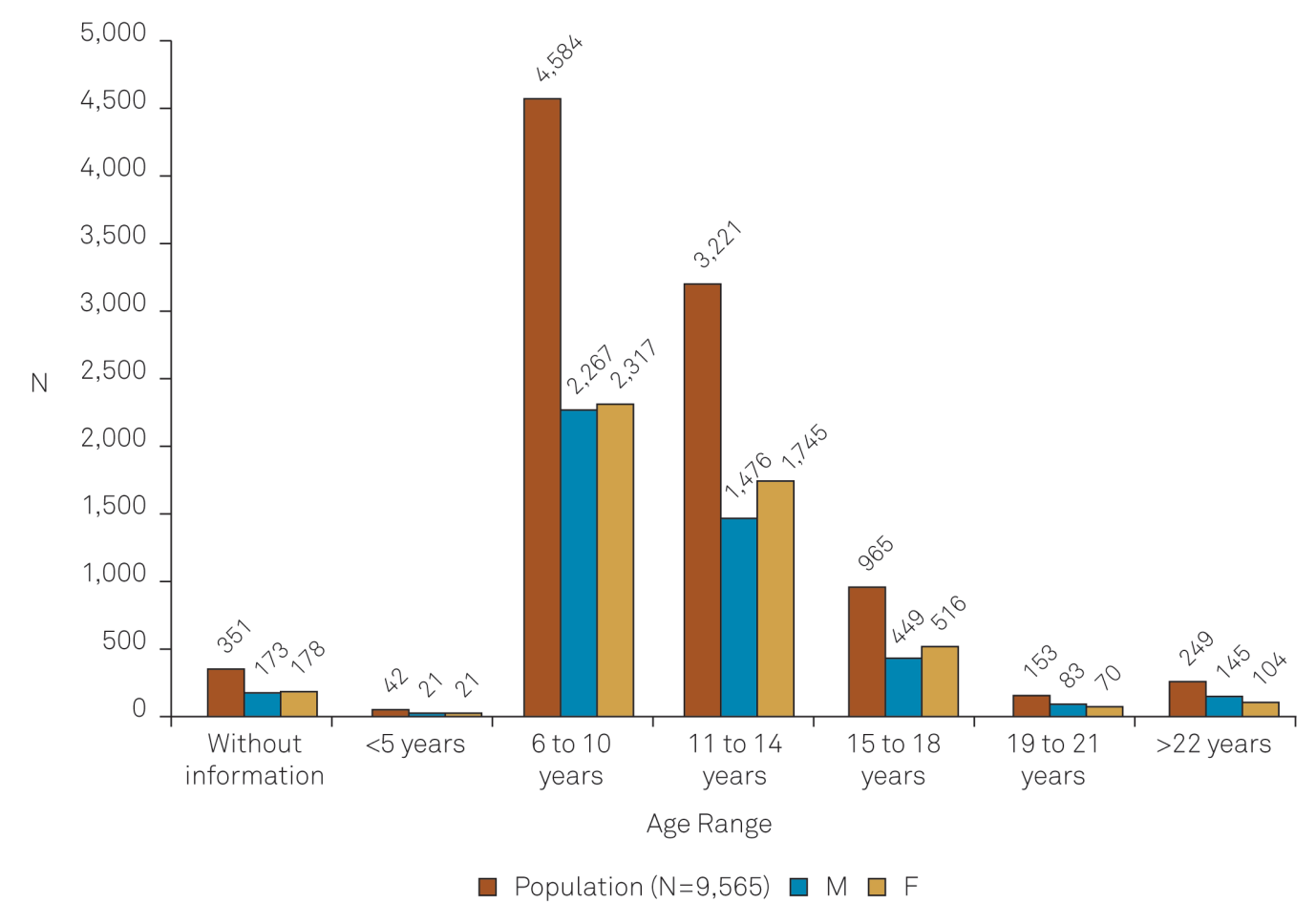

Figure 1. Screened population $(N=9,565)$. 


\section{Direct interviews phase}

We intended to begin this phase one year after we had collected the questionnaires, but it only started 2 years after that, due to a strike in the public school system. We returned to the schools and asked the directors to call up all the students feasible to come to the direct interview. We didn't take those students screened with response "no tics" into account as we considered that the teachers' assistence would minimize the negative responses. Many times the interviewer needed to return to a specific school to perform the interview and in all these times reconvocation of positive screened students that never came was redone. Firstly we dealt with students whose responses to the questionnaire were "concurrent positive answer for simple motor, complex motor and vocal tics" (group 1) and after with group 2 (responses for any possibility, except those of the previous group). In this phase, the first author (HLA) personally interviewed all the subjects that came to the interview. We made use of additional structured questionnaires with the presence of at least one of the parents and the student him/herself for history collection and clinical observation for tics diagnose. If tics were present the term "definite" was attached. If not seen in direct examination but reliable by history and/or confirmed by the student's teacher when necessary, the term "by history" was attached. A trained medical student (APD), able to recognize tics, participated in this part of the study and the interviews took place in the same room the first author performed the interviews, so any doubt could be discussed at that moment. The identified tic subject was, again, revised by the first author (HLA). From groups 1 and 2 emerged a "TS group" who was followed up by a mean period of 4.6 years and "other tics, except TS, group" followed up then by a mean period of 2.3 years.

\section{Data analysis}

Data were organized in a D-Base software, and analyzed by using the SAS system 6.12 (statistical analysis system). Mean, standard deviation, median were calculated for the "TS subjects group" and "tic disorders, except TS, group", regarding samples age, age onset of symptomatology and continuity of tics. The prevalence was calculated by dividing the number of cases by the total number of screened students.

\section{RESULTS}

Out of 15,000 questionnaires, 10,155 (4,918 M, 5237 F) were given back. The answer "no tic present" occurred in 6,211 questionnaires $(61.16 \%)(2943 \mathrm{M}, 3268 \mathrm{~F})$ and 590 questionnaires (5.8\%) (304 M, 286 F) returned without any answer. Consequently there were 9,565 questionnaires
(4,614 M, 4951 F) with "valid answers" (Figure 1). Out of these, 3,354 questionnaires (38.3\% - 1,671 M and 1,683 F) with positive answers for tics and 6,211 (61.16\%) with "no tics"/"no repeated bad thoughts or ideas in mind" response.

The 3,354 screened questionnaires were divided into two groups: a group 1 with "concurrent response for simple motor tics, complex motor tics and vocal tics (simple or complex)" (486 subjects), and a group 2 with "responses for any possibility, except those of the previous group" (2,868 subjects). From all those subjects invited to direct interview, for at least three times, 223 subjects $(129 \mathrm{M}$, $94 \mathrm{~F})$ from group 1 were present and 539 subjects $(257 \mathrm{M}$, $282 \mathrm{~F}$ ) from group 2 were present.

We interviewed thereafter, a total of 762 students (22.7\% of 3,354 positive questionnaires) being $386 \mathrm{M}$ and $376 \mathrm{~F}$, with the results summarized in Figure 2. Sample size groups were representative of the population. Age 6 to 18 encompassed $95 \%$ of the studied sample. Obsessive-compulsive symptoms patients were excluded.

These data revealed a total mean minimal TS prevalence of $0.43 \%$ (42 subjects) considering both sexes, with age 9 reaching $1 \%$. TS prevalence by specific age is in Figure 3 . When sexes were considered separately, we observed a prevalence of $0.67 \%$ for male and $0.22 \%$ for female.

If we put together chronic multiple tic disorder (63 subjects), chronic simple tic disorder (87 subjects), probable TS (5 subjects) and probable CMTD (62 subjects) there is a prevalence of $2.27 \%$. By gathering transient tic disorder (19 subjects), the prevalence is $2.47 \%$. Thus, the overall minimal prevalence for Tourette syndrome and additional tic disorders, including non-specific tic disorder (1 subject), is $2.91 \%$.

\section{DISCUSSION}

Community studies encompassing the age range in which there are a natural decreasing of tics have pointed to a low TS prevalence of $0.1 \%$ or even $0.043 \%^{2,4}$. Particularly concerning the Israel study it is of worthwhile review the considerations of Fallon and Schwab-Stone ${ }^{8}$.

The highest reported TS prevalences of $3.8 \%$ and $5.26 \%$ are explained in the former possibly by the duration of tics that could not be ascertained and in the later possibly by their small screened sample, despite its sophisticated methodology. Also, the CMTD-to-TS proportion $(0.8 \%$ CMTD/3.8\% TS) is inverted in the former, and too close in the later $(7.28 \% \mathrm{CMTD} / 5.26 \% \mathrm{TS})$. CMTD is expected to be far more frequent than TS, at the order of 2.7 to 7 times more frequent ${ }^{9}$.

Our $0.43 \%$ TS prevalence is higher than the $0.36 \%$ TS of Coming's et al., which is a longitudinal study with follow-up ${ }^{10}$. It is similar to the $0.5 \%$ of Nomoto \& Machiama 


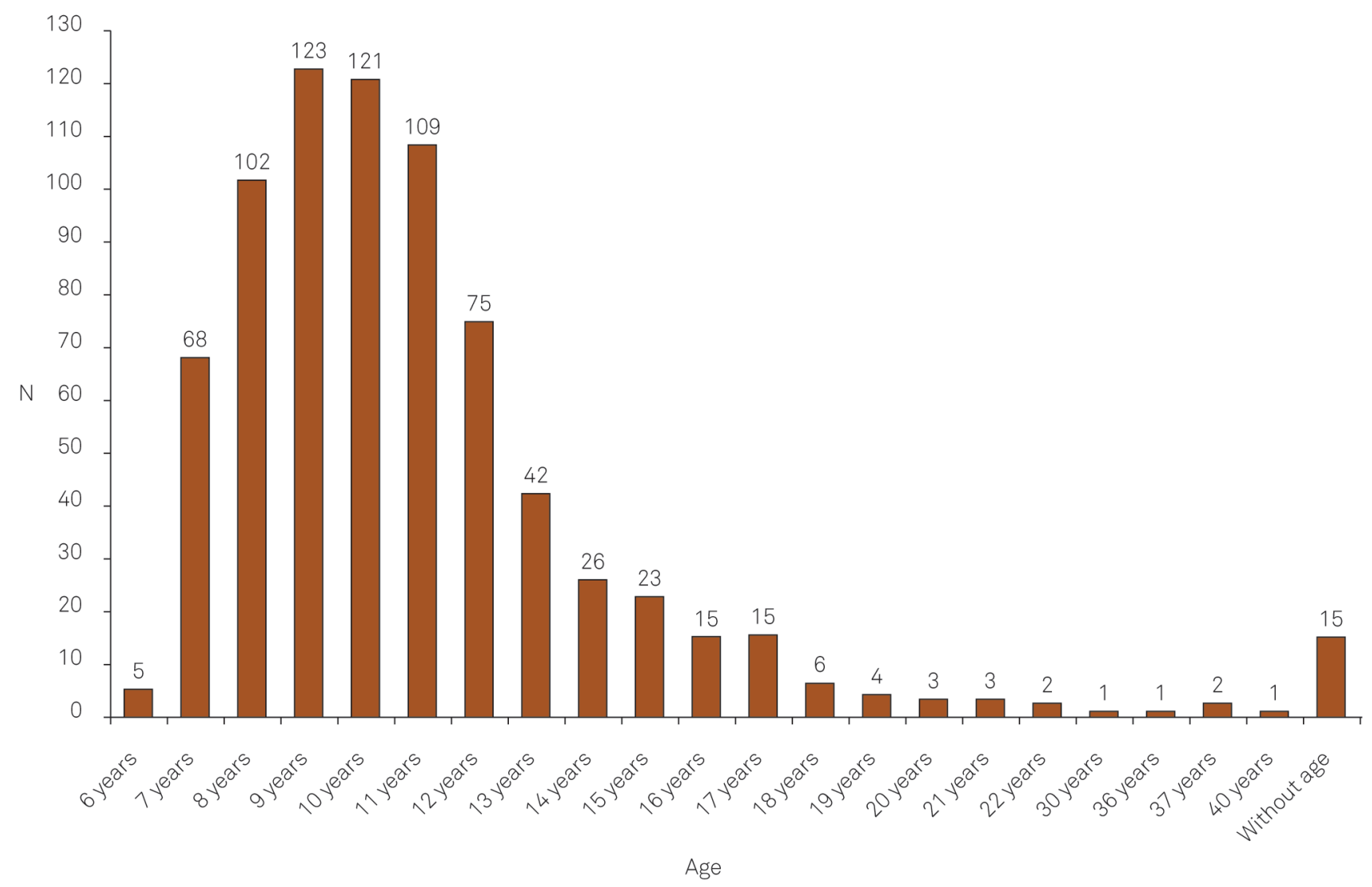

Figure 2. Studied sample: 762 students (N).

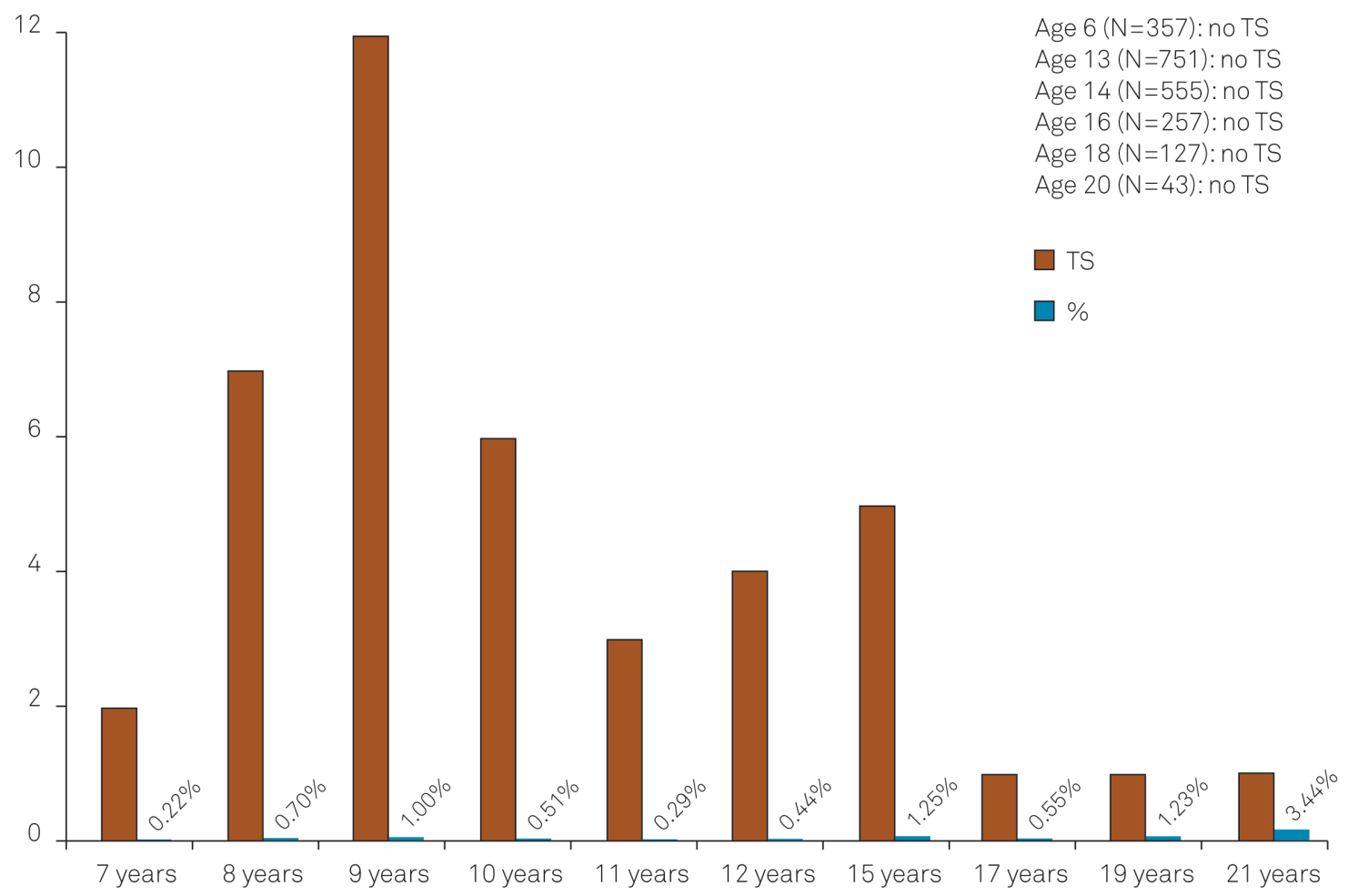

Figure 3. TS prevalence by specific age - 42 subjects. 
and $0.4 \%$ of Wong \& Joseph studies, although these studies had no follow up ${ }^{11,12}$, and no direct interview in the Japanese study. It is different from the Swedish study of Landgreen et al.'s (0.34\% TS) in an age range of 6.4-6.8 years ${ }^{13}$. The small population screened (589 children), the possibility of chance finding TS subjects among them, the low age range of their sample in which TS symptoms are just beginning, may explain their prevalence. It also differs from Costellos's $(0.1 \%$ TS), just in a age range that tics and TS reach their peak and curiously the same TS prevalence $(0.1 \%)$ reported by Verhulst et al. in the age range when tics and TS symptomatology are decreasing $(1,2)$. A possible explanation for their low prevalence may be to the fact that it was designed to identify children with high probability of mental health service use. Indeed, the study 2 (clinical setting: $0.1 \%$ TS) of Kadesjö and Gillberg ${ }^{14}$, directed to screen children with clinically significant neuropsychiatry disorders, give support to Costello et al.'s study.

Considering the Kadesjö study 1 which reports a 1.1\% TS prevalence, but excluding two cases of special education needs, it turns to $0.68 \%$, which is similar to our study (7 to 11 years, 32 TS/5,239 students, $0.61 \%$ ), and similar to that reported by Hornsey et al.'s of $0.76 \%$ which excluding one special student case turns their prevalence to $0.65 \%{ }^{15}$.

Despite Hornsey's study being a point prevalence study and our study a longitudinal one, similarities indeed exist. For instance, their age range 13-14 years old correspond to our 9-10 years old students at the baseline of our study (year 1992) who after a mean follow up period of 4.6 years were in the range of 13-14 years. In this age group (9-10 years) our minimal TS prevalence is of $0.76 \%$ (2,353 students/18 TS) (Figure 3). Both studies employed easily understandable screening questionnaires for tic identification. Instead of telephone contact we personally interviewed the positive responders in a second stage, and finally, in a third stage, we interviewed and followed them up at their homes. Also similar in both studies is the false positives questionnaires responses at the level of $46.7 \%$ in Hornsey study and $47.8 \%$ in our group 1, and also similar to the $48.5 \%$ reported by Nomoto's. This also occurred in Linazosoro et al.'s study (42\% false positives) and Stefanoff's study (82\%, see results section $)^{16,17}$. In relation to the high false positive responders in our group $2(67.5 \%)$ it is explained by the long interval time elapsed from the screening phase to the direct interview phase that caused some doubts about diagnosis of TTD. In the interview many subjects had not certainty about duration of the tics they had described, which made us not compute them as TTD. If included, the false positive would be around $50 \%$. This is the reason our TTD prevalence is too low. We think the best design to ascertain TTD prevalence is a point prevalence study. It is of value to have in mind that it is impossible for a subject (responders) to understand that the tic disorder we are looking for must meet a constellation of symptoms that are grouped in the DSM-III-R or the TSCSG or DSM IV 6 ,7,18,19.

When analysing the DSM IV Swedish study of Kalifa and vonKnorring, we believe that their $0.5 \%$ TS prevalence (regular students) is high specially having employed DSM IV with its impairment $\mathrm{C}$ criteria $^{20}$. As being a one year prevalence study with $87 \%$ of their subjects having only one tic period, it implicates that these subjects should have had a more extended follow up period to categorize better TS subjects. Still, their CMTD to TS proportion (1.3\% CMTD/0.5\% TS) is too close.

Regarding the $0.56 \%$ TS prevalence of Wang and Kuo, the $0.68 \%$ probable TS of Lanzi et al., and the $0.43 \%$ TS of Jin et al., we see that they report similar TS prevalence when comparing to our study ${ }^{21,22,23}$. The $0.56 \%$ TS prevalence of the Taiwanese study is close to our $0.52 \%$ TS prevalence for the same age range (6,499 students/34 TS). Also, the $0.68 \%$ TS prevalence of Lanzi et al. is not far from our $0.52 \%$ TS prevalence in the same age range (6,536 students/ 34 TS). Although they considered probable TS as TS, this is not the same, according to the TSCSG. Other relevant fact, recognized by the authors as a flaw, is that they did not interview those students screened positive. For instance, in our tic disorder group we had 5 probable TS that never turned to TS subjects after a 4.6 years follow up period. Comparing our study to the Chinese study of Jin et al. their mean $0.43 \%$ is quite similar to our $0.47 \%$ TS prevalence for the same age range (8,105 students/38 TS).

Also a community study, Stefanoff et al. in Warsow, reported a $0.6 \%$ TS prevalence $(0.44 \%$ with sp-students excluded, similar to our), in which they excluded mentally retarded children but included special integration classes for disabled children and among 9 TS there were 2 with neurological syndromes ${ }^{17}$. More recently, Scahill et al. reported a $0.3 \%$ TS prevalence in a community study and in a random telephone interview survey with parents, which they believe, in both studies, to be underestimated ${ }^{24,25}$.

Still, a meta-analysis study reports a $0.77 \%$ TS prevalence and $2.34 \%$ prevalence for both CVTD+CMTD in 13 and 4 school-based studies respectively, is congruent with our results ${ }^{26}$.

Finally, two recent school-based studies, an Iranian (mean age: 9.5) and one in Mauritius (9-11 years age), report respectively $1.3 \%$ and $0.6 \%$ TS prevalence, also similar to our results considering that age range $\mathrm{e}^{27,28}$.

Our prevalence for "other tic disorders, except TS" is of $2.47 \%$ including CMTD (0.66\%), CSTD (0.91\%), TTD (0.2\%), probable CMTD (0.65\%) and probable TS $(0.05 \%)$, following the $\mathrm{TSCSG}^{7}$. For only chronic tic disorders [excluding TTD $(0.2 \%)$ o our $2.27 \%$ is similar to $2.31 \%$ of Scahill et al.' $\mathrm{s}^{24}$ and not so different from the $1.8 \%$ reported by Verhulst and Zohar studies, ${ }^{2,29}$. Also, the $2.5 \%$ CTD reported by Stefanoff et al. is quite similar to our study that is $2.27 \%{ }^{17}$. 
Surely our $0.2 \%$ TTD prevalence is underestimated, as exposed above. By taking all tic disorders into account, the overall minimal prevalence in our study is of $2.91 \%$, a finding very similar to $2.86 \%$ of Nomoto and $2.9 \%$ of Lanzi ${ }^{11,22}$.

We didn't work with those who screened negative as we considered that the teachers help to parents to fill out the questionnaires, with direct assistence to them, could minimize the number of false negative responses. So, we refer to our results as minimal estimated prevalence.

In conclusion, we believe that our community study provides a realistic contribution to TS and tic disorders prevalence ascertainment as it was extracted from a representative sample of schools of all regions of the city, encompassing both the age range when tics reach their peak and that when they decrease. Still, it is strongly tied to the suggestions TS researchers have given to those who enter the field of tic disorders epidemiology, as to say, the design of such a community based study must include a wide age range in the school age population, to ensure that the full range of tic symptoms and their onset can be documented, ascertaining the persistence of tics over an enduring period of time preferably by an experienced clinician ${ }^{10,30}$.

\section{Acknowledgments}

We are grateful to Ana Paula Damiano, a medical student who diligently helped us at the time of data collection. We are also grateful to Antonio Amarante for the data statistical analyses.

\section{References}

1. Costello EJ, Angold A, Burns BJ, Stangl DK, Tweed DL, Erkanli A et al. The Great smoky mountains study of youth. Goals, design, methods and the prevalence of DSM-III-R disorders. Arch Gen Psychiatry. 1996;53(12):1129-36. http://dx.doi.org/10.1001/archpsyc.1996.01830120067012

2. Verhulst FC, End J, Ferdinand RF, Kasius MC. The prevalence of DSM-III-R diagnoses in a national sample of dutch adolescents. Arch Gen Psychiatry. 1997;54(4):329-36. http://dx.doi.org/10.1001/ archpsyc.1997.01830160049008

3. Kurlan R, McDermot MP, Deeley C, Como PG, Brower C, Eapen S et al. Prevalence of tics in school children and association with placement in special education. Neurology. 2001,57(8):1383-8. http://dx.doi.org/ 10.1212/wnl.57.8.1383

4. Apter A, Pauls DL, Bleich A, Zohar AH, Kron S, Ratzoni G et al. An epidemiologic study of Gilles de La Tourette's syndrome in Israel. Arch Gen Psychiatry. 1993;50(9):734-8. http://dx.doi.org/10.1001/ archpsyc.1993.01820210068008

5. Cubo E, Gabriel y Galán JMT, Villaverde VA, Velasco SS, Benito VC, Macarrón JV et al. Prevalence of tics in schoolchildren in Central Spain: a population-based study. Pediatr Neurol. 2011;45(2):100-8. http://dx.doi.org/10.1016/j.pediatrneurol.2011.03.003

6. American Psychiatric Association. Diagnostic and statistical manual of mental disorders. 3rd ed. rev. Washington, DC: American Psychiatric Association; 1987.

7. The Tourette Syndrome Classification Study Group. Definitions and classification of tic disorders. Arch Neurol. 1993;50(10):1013-6. http://dx.doi.org/10.1001/archneur.1993.00540100012008

8. Fallon T Jr, Schwab-Stone M. Methodology of epidemiological studies of tic disorders and comorbid psychopathology. Adv Neurol. 1992;58:43-53.

9. Shapiro AK, Shapiro ES, Young JG, Feinberg TE. Gilles de La Tourette syndrome. New York: Raven; 1988.

10. Comings DE, Himes JA, Comings BG. An epidemiologic study of Tourette syndrome in a single school district. J Clin Psychiatry. 1990;51(11):463-9.

11. Nomoto F, Machiyama Y. An epidemiologic study of tics. Jpn J Psychiatr Neurol. 1990;44(4):649-55. http://dx.doi.org/10.1111/ j.1440-1819.1990.tb01641.x

12. Wong CK, Lau JTF. Psychiatry morbidity in a Chinese primary scholl in Hong Kong. Aust N Z J Psychiatr 1992;26(3):459-66. http://dx.doi.org/ 10.3109/00048679209072071
13. Landgren M, Petterson R, Kjellman B, Gillberg C. ADHD, DAMP and other neurodevelopmental / psychiatric disorders in 6-year-old children: epidemiology and co-morbidity. Dev Med Child Neurol. 1996;38(10):891-906. http://dx.doi.org/10.1111/j.1469-8749.1996. tb15046.x

14. Kadesjö B, Gillberg C. Tourette's disorder: epidemiology and comorbidity in primary school children. J Am Acad Child Adolesc Psychiatry. 2000;39(5):548-55. http://dx.doi.org/10.1097/00004583200005000-00007

15. Hornsey H, Banerjee S, Zeitlin H, Robertson M. The prevalence of Tourette syndrome in 13-14-year-olds in mainstream schools. $J$ Child Psychol Psychiatry 2001;42(8):1035-9. http://dx.doi.org/ 10.1111/1469-7610.00802

16. Linazasoro G, Van Blercom N, Zárate CO. Prevalence of tic disorder in two schools in the Basque country: results and methodological caveats. Mov Disord. 2006;21(12):2106-9. http://dx.doi.org/10.1002/ mds. 21117

17. Stefanoff P, Wolanczyk T, Gawrys A, Swirszca K, Stefanoff E, Kaminska $A$ et al. Prevalence of tic disorders among schoolchildren in Warsow, Poland. Eur Child Adolesc Psychiatry. 2008;17(3):171-8. http://dx.doi.org/10.1007/s00787-007-0651-y

18. American Psychiatric Association. Diagnostic and statistical manual of psychiatry. 4th ed. Washington, DC: American Psychiatric Association; 1994

19. Tanner CM, Goldman SM. Epidemiology of Tourette Syndrome. Neurol Clinics. 1997;15(2):395-402. http://dx.doi.org/10.1016/s07338619(05)70320-0

20. Khalifa N, Knorring AL. Prevalence of tic disorders and Tourette syndrome in a Swedish school population. Dev Med Child Neurol. 2003;45(5):315-9. http://dx.doi.org/10.1017/s0012162203000598

21. Wang H-S, Kuo M-F. Tourette's syndrome in Taiwan: an epidemiological study of tic disorders in an elementary school at Taipei County. Brain Develop. 2003;25 Suppl 1:S29-31. http://dx.doi.org/ 10.1016/s0387-7604(03)90005-2

22. Lanzi G, Zambrino CA, Termine C, Palestra M, Ferrari Ginevra O, Orcesi $S$ et al. Prevalence of tic disorders hmong primary school students in the city of Pavia, Italy. Arch Dis Child. 2004;89(1):45-7.

23. Jin $\mathrm{R}$, Zheng RY, Huang $W W, X u H-Q$, Shao $B$, Chen $H$ et al. Epidemiological survey of Tourette syndrome in children and adolescents in Wenzhou of P.R. China. Eur J Epidemiol. 2005;20(11):925-7. http://dx.doi.org/10.1007/s10654-005-2953-z 
24. Scahill L, Williams S, Schwab-Stone M, applegate J, Leckan JF et al. Disruptive behavior problems in a community sample of children with tic disorders. Adv Neurol. 2006;99:184-90.

25. Scahil L, Bitsko RH, Visser SN, Blumberg SJ. Prevalence of Diagnosed Tourette Syndrome in persons aged 6-17 years - United States. MMWR Morb Mortal Wkly Rep. 2009;58(21):581-5.

26. Knight T, Steeves T, Day L, Lowerison M, Jette N, Pringsheim T. Prevalence of tic disorders: a systematic review and meta-analysis. Pediatr Neurol. 2012;47(2):77-90. http://dx.doi.org/10.1016/j.pediatrneurol.2012.05.002

27. Amiri S, Fakhari A, Golmirzaei J, Mohammadpoorasi A, Abdi S. Tourette's syndrome, chronic tics, and comorbid attention deficit /hyperactivity disorder in elementary students. Arch Iran Med. 2012;15(2):76-8.

28. Chummun $\mathrm{V}$. The prevalence of tic disorder in an electoral district of Mauritius. J Neurol Neurosurg Psychiatry. 2014;85:e3. http://dx.doi. org/10.1136/jnnp-2014-308883.22

29. Zohar AH, Ratzoni G, Pauls DL, Apter A, Bleich A, Kron S et al. An epidemiologic study of obsessive-compulsive disorder and related disorders in Israeli adolescents. J Am Acad.Child Adolesc Psychiatry. 1992;31(6):1057-61. http://dx.doi.org/10.1097/00004583199211000-00010

30. Scahill L, Tanner C, Dure L. The epidemiology of tics and Tourette syndrome in children and adolescents. Adv Neurol. 2001;85:261-71. 